\title{
Papers
}

\section{Immediate and long term effects of weight reduction in obese people with asthma: randomised controlled study}

\author{
Brita Stenius-Aarniala, Tuija Poussa, Johanna Kvarnström, Eeva-Liisa Grönlund, Mikko Ylikahri, \\ Pertti Mustajoki
}

\begin{abstract}
Objective To investigate the influence of weight reduction on obese patients with asthma.

Design Open study, two randomised parallel groups.

Setting Private outpatients centre, Helsinki, Finland.

Participants Two groups of 19 obese patients with

asthma (body mass index $\left(\mathrm{kg} / \mathrm{m}^{2}\right) 30$ to 42$)$ recruited

through newspaper advertisements.

Intervention Supervised weight reduction

programme including 8 week very low energy diet.

Main outcome measures Body weight, morning peak expiratory flow (PEF), forced vital capacity (FVC), forced expiratory volume in one second $\left(\mathrm{FEV}_{1}\right)$; and also asthma symptoms, number of acute episodes, courses of oral steroids, health status (quality of life).

Results At the end of the weight reducing programme, the participants in the treatment group had lost a mean of $14.5 \%$ of their pretreatment weight, the controls $0.3 \%$. The corresponding figures after one year were $11.3 \%$ and a weight gain of $2.2 \%$. After the 8 week dieting period the difference in changes in percentage of predicted $\mathrm{FEV}_{1}$ from baseline in the treatment and control groups was $7.2 \%$ (95\% confidence interval $1.9 \%$ to $12.5 \%$, $\mathrm{P}=0.009)$. The corresponding difference in the changes in FVC was $8.6 \%$ (4.8\% to $12.5 \%, \mathrm{P}<0.0001)$. After one year the differences in the changes in the two groups were still significant: $7.6 \%$ for $\mathrm{FEV}_{1}(1.5 \%$ to $13.8 \%, \mathrm{P}=0.02)$ and $7.6 \%$ for $\mathrm{FVC}(3.5 \%$ to $11.8 \%$, $\mathrm{P}=0.001)$. By the end of the weight reduction programme, reduction in dyspnoea was $13 \mathrm{~mm}$ (on a visual analogue scale $0 \mathrm{~mm}$ to $100 \mathrm{~mm}$ ) in the treatment group and $1 \mathrm{~mm}$ in the control group $(\mathrm{P}=0.02)$. The reduction of rescue medication was 1.2 and 0.1 doses respectively $(\mathrm{P}=0.03)$. After one year the differences in the changes between the two groups were -12 for symptom scores (range -1 to -22 , $\mathrm{P}=0.04)$ and -10 for total scores $(-18$ to -1 , $\mathrm{P}=0.02)$. The median number of exacerbations in the treatment group was $1(0-4)$ and in the controls 4 $(0-7), \mathrm{P}=0.001$.
\end{abstract}

Conclusion Weight reduction in obese patients with asthma improves lung function, symptoms, morbidity, and health status.

\section{Introduction}

Obesity is an increasing health problem worldwide. Currently, 30-50\% of the adult population in affluent countries is overweight (body mass index (weight $(\mathrm{kg})$ / $\left.(\text { height }(\mathrm{m}))^{2}\right)>25$, with $10-20 \%$ of all adults being at least moderately obese $(>30) .{ }^{1}$ Obesity and asthma are not known to be causally associated, but because of the high prevalence of obesity a large number of asthmatic people will be obese. Obesity may affect lung function ${ }^{2}$ and so cause worsening of the asthma. The mechanisms by which weight loss can alleviate asthma may include alleviation of airway collapse, stimulation of adrenal activity, and reduction in possible allergens, bronchoconstrictors, or salt content in the diet. We investigated whether weight loss affects lung function, morbidity, symptoms, or health status in obese asthmatic people.

\section{Participants and methods}

The participants, recruited by advertisements in two daily newspapers, were obese and asthmatic. Inclusion criteria were ability to cope with the study protocol, body mass index $30-42$, age $18-60$ years, previously diagnosed asthma with a spontaneous diurnal variation or a bronchodilator response of $15 \%$ or more, and being a non-smoker or having stopped smoking for two years or more before age 50 . Exclusion criteria were pregnancy, history of bulimia or anorexia, unstable angina or arrhythmia, untreated thyroid disease, symptomatic liver or gall bladder disorder, any other severe disease, insulin treatment, systemic steroid treatment, or history of food allergy or of intolerance to any component of the very low energy dietary preparation that would be used in the study-such as soya, fish, chocolate, or lactose. Participants with a history of adverse reactions to peas, beans, or peanuts were excluded because of possible cross reactions to soya protein. ${ }^{3}$

Telephone interviews were held with 202 potential participants; 133 were excluded (see fig A, a flow chart showing exclusions, on the BMJ's website), and the remaining 69 were invited for further evaluation. These 69 potential participants underwent a personal interview and a clinical check up, and their inhalation technique was checked. Antiasthmatic medication was not changed if the stability of the asthma was clinically

\begin{tabular}{l} 
Division of \\
Pulmonary \\
Medicine and \\
Allergology, \\
Helsinki University \\
Central Hospital, \\
FIN-00029 HYKS, \\
Helsinki, Finland \\
Brita \\
Stenius-Aarniala \\
professor of \\
pulmonary medicine \\
Johanna \\
Kvarnström \\
medical student \\
Mikko Ylikahri \\
licentiate in medicine \\
STAT-Consulting, \\
Takojankatu 15 B, \\
FIN-33540 \\
Tampere, Finland \\
Tuija Poussa \\
statistics consultant \\
Peijas Hospital, \\
Sairaalakatu 1, \\
FIN-01400 Vantaa, \\
Finland \\
Eeva-Liisa \\
Grönlund \\
consultant in \\
pulmonary medicine \\
Pertti Mustajoki \\
consultant in \\
pulmonary medicine \\
Correspondence to: \\
B Stenius-Aarniala, \\
Department of \\
Medicine, PL 340 \\
Helsinki, University \\
Central Hospital, \\
FIN-00029 HYKS, \\
Finland \\
bstenius@cc. \\
helsinki.fi \\
BMJ 2000;320:827-32 \\
Website \\
eXtra \\
A chart showing \\
the flow of \\
participants and a \\
table showing \\
baseline \\
characteristics are \\
BMJlable on the \\
\hline wwebsite \\
\end{tabular}


acceptable. In six cases medication had to be intensified. During the baseline period and the study period, medication was changed only during episodes of exacerbation of the asthma. One participant with an uncertain history of allergy to peas and beans was excluded because a test dose of the dietary preparation caused immediate allergic symptoms.

After a two to three week run-in period with lung function measurements and laboratory tests, 38 participants fulfilled the inclusion criteria (see BMJ's website for flow chart showing exclusions). After two weeks of baseline measurements, the participants were randomised to a treatment group (19) and a control group (19). Randomisation was by "shuffling cards," with the help of someone not involved in the study. Clinical data are presented in table A on the BMJ's website.

The treatment group took part in a weight reduction programme that included 12 group sessions and lasted 14 weeks, including eight weeks-"the dieting period"-in which participants took a very low energy dietary preparation (Nutrilett (Nycomed Pharma, Oslo)). The daily dose gave $1760 \mathrm{~kJ}$ of energy and contained daily allowances of all essential nutrients, as described elsewhere. ${ }^{4}$ The principles and behaviour methods of this weight reduction programme are also described elsewhere. ${ }^{56}$ The control group had sessions at the same intervals as the treatment group; each session lasted half an hour, during which time themes chosen by the group were discussed freely. These themes were discussed with the treatment group at later sessions; by the end of the first year each group had had the same amount of education about asthma and allergy.

All participants received normal medical care throughout the study. Using a mini-Wright peak flow meter and taking the best of three consecutive blows into account, the participants measured their daily morning and evening pre-bronchodilator and postbronchodilator peak expiratory flow (PEF) during the dieting period, and thereafter during the two weeks before each group meeting. The mean of the previous two weeks' premedication PEF values served for calculation. Forced vital capacity (FVC) and forced expiratory volume in one second $\left(\mathrm{FEV}_{1}\right)$ were measured by means of a mini-Wright spirometer at baseline, at the end of the dieting period, at the end of the 14 week weight reduction programme, at six months, and at one year. During the peak flow follow up periods, asthma symptoms were recorded on a $100 \mathrm{~mm}$ visual analogue scale (where $0 \mathrm{~mm}$ represented "best possible" and $100 \mathrm{~mm}$ "worst possible") and rescue medication was recorded as the number of daily doses of an inhaled bronchodilator. Serum cortisol and diurnal urine cortisol excretion concentrations and blood and urine concentrations of sodium, potassium, calcium, magnesium, triglycerides, and cholesterol were measured at baseline, at the end of the dieting period, and after 14 weeks. Health status was investigated four times during the first year, using the St George's respiratory questionnaire, which is divided into three parts: symptoms (distress caused by specific respiratory symptoms); activity (physical activities that cause or are limited by breathlessness); and impact (social and psychological effects of the disease). The total score is derived from all items and is expressed as a percentage of the maximum possible. A decrease in the score indicated an improvement in health status. A translated Finnish version of this questionnaire has been used previously. ${ }^{7}$ The data from the questionnaires on health status were compiled with the help of software designed by P W Jones (St George's Hospital, London). All 38 participants were followed for one year. Two participants found the consistency or taste of the dietary preparation intolerable but followed a low energy diet; one participant started smoking during the study. These three participants were retained in the study.

\section{Statistical analysis}

Determination of sample size was based on the change in daily PEF $(1 / \mathrm{min})$. It was originally assumed that PEF would increase by $50 \mathrm{l} / \mathrm{min}$ in the treatment group and by $20 \mathrm{l} / \mathrm{min}$ in the control group. It was assumed that a difference in change of 30 litres or more between the groups would be clinically significant. ${ }^{8}$ To demonstrate this, with a standard deviation of $25 \mathrm{l} / \mathrm{min}$, $\alpha$ error of $5 \%$, and a power of $90 \%, 15$ participants per group were required to complete the study. ${ }^{9}$ However, owing to chance, the baseline difference between the groups was 36 litres (treatment group, 423 litres; control group, 387 litres)-that is, greater than the expected treatment difference. Also owing to chance, the proportion of men was higher in the treatment group, which can explain the baseline differences expressed in litres. To control for the possible differences in sex, age, and height distributions, the analysis was based on percentage of predicted values. ${ }^{11}{ }^{11}$ The groups were similar for these baseline values and for all other participant characteristics except rhinitis (see table A on website). The mean numbers of PEF recordings were 13.9 (range 12-14), 13.6 (7-14), 13.7 (11-14), 13.3 (5-14) and 13.7 (8-14) for the five two-week periods. The mean of all usable PEF recordings was used as the mean value for the period.

The data were analysed by means of StatView 512 + TM (Brainpower) for Apple Macintosh and SPSS 9.0 for Windows. The changes from baseline were calculated for lung function, and the $t$ test for independent samples was used to compare the treatment group with the control group. The $95 \%$ confidence intervals were calculated for change within a treatment group and for difference between groups. Changes in symptoms and use of rescue sympathomimetics were analysed by the non-parametric Mann-Whitney $U$ test. Changes in health status subscores and in laboratory variables were analysed by the $t$ test for independent samples. The $\chi^{2}$ test was used for binary variables.

\section{Secondary analyses}

Secondary analyses were performed to control for the multiplicity of data. Analysis of variance for repeated measurements was performed to compare the changes from baseline in the lung function variables in the two study groups. We studied $(a)$ the difference between study groups; (b) the time effect-that is, change during the follow up period; and $(c)$ interaction between group and time effect. Repeated measurements of symptoms (dyspnoea, cough) and use of sympathomimetics during the follow up were reduced to the mean of all measurements, and the overall changes from baseline were calculated. The Mann-Whitney U test was used to compare the treatment group with controls. 
Mean change in percentage of predicted morning peak expiratory flow (PEF), forced expiratory volume in one second (FEV $\left.{ }_{1}\right)$, and forced vital capacity (FVC) from baseline to end of very low energy diet (dieting period), end of weight reduction programme, and follow up visits at 6 months and 1 year. Values in parentheses are 95\% confidence intervals

\begin{tabular}{|c|c|c|c|c|}
\hline & $\begin{array}{l}\text { Change in } \\
\text { treatment group }\end{array}$ & $\begin{array}{l}\text { Change in } \\
\text { control group }\end{array}$ & $\begin{array}{l}\text { Difference between } \\
\text { treatment and control }\end{array}$ & P value* \\
\hline \multicolumn{5}{|l|}{ PEF ( $\%$ of predicted): } \\
\hline End of dieting period & 6.1 (2.4 to 9.7$)$ & $1.3(-2.5$ to 5.1$)$ & $4.8(-0.3$ to 9.8$)$ & 0.06 \\
\hline End of weight reduction programme & $4.5(-0.9$ to 9.8$)$ & $-0.3(-4.6$ to 4.1$)$ & $4.8(-1.9$ to 11.4$)$ & 0.16 \\
\hline 6 months & $4.1(-1.5$ to 9.8$)$ & $-0.6(-5.5$ to 4.3$)$ & $4.7(-2.5$ to 11.9$)$ & 0.19 \\
\hline 1 year & $5.6(-0.2$ to 11.4$)$ & $-0.6(-5.8$ to 4.7$)$ & $6.2(-1.4$ to 13.7$)$ & 0.11 \\
\hline \multicolumn{5}{|l|}{$\mathrm{FEV}_{1}(\%$ of predicted): } \\
\hline End of dieting period & $7.3(3.5$ to 11.1$)$ & $0.1(-3.8$ to 4.0$)$ & $7.2(1.9$ to 12.5$)$ & 0.009 \\
\hline End of weight reduction programme & $5.3(2.2$ to 8.4$)$ & -1.5 (-5.1 to 2.2$)$ & 6.7 (2.1 to 11.4$)$ & 0.006 \\
\hline 6 months & $6.5(2.3$ to 10.7$) \dagger$ & $-1.9(-4.7$ to 0.8$)$ & $8.4(3.7$ to 13.2$)$ & 0.001 \\
\hline 1 year & $4.9(-0.5$ to 10.3$)$ & $-2.7(-5.9$ to 0.5$) \dagger$ & $7.6(1.5$ to 13.8$)$ & 0.02 \\
\hline \multicolumn{5}{|l|}{ FVC (\% of predicted): } \\
\hline End of dieting period & $3.4(0.8$ to 6.1$)$ & $-5.2(-8.2$ to -2.2$)$ & $8.6(4.8$ to 12.4$)$ & $<0.0001$ \\
\hline End of weight reduction programme & $1.9(-0.7$ to 4.4$)$ & $-5.6(-9.6$ to -1.5$)$ & $7.4(2.8$ to 12.1$)$ & 0.002 \\
\hline 6 months & $1.7(-1.3$ to 4.7$) \dagger$ & $-6.0(-8.2$ to -3.7$)$ & 7.6 (4.1 to 11.2$)$ & 0.0001 \\
\hline 1 year & $2.0(-1.4$ to 5.4$)$ & $-5.6(-8.2$ to -3.1$) \dagger$ & 7.6 (3.5 to 11.8$)$ & 0.001 \\
\hline
\end{tabular}

*Difference between changes from baseline in treatment group and control group †Based on results from 18 patients.

\section{Results}

\section{Weight reduction}

Mean weight reduction in the treatment group was $14.2 \mathrm{~kg}$ (range $7.7-22.1 \mathrm{~kg}$ ), or $14.5 \%$ of pretreatment weight at the end of the weight reduction programme. At this point, nine participants had lost $\geqslant 15 \%$ of their weight, eight participants $10.0-14.9 \%$, and two participants $5.0-9.9 \%$. After one year the mean weight reduction was $11.1 \mathrm{~kg}(1.1-22.5 \mathrm{~kg})$, or $11.3 \%$. In the control group the corresponding changes in weight were small-a mean weight loss of $0.3 \mathrm{~kg}$ at the end of the programme and a mean gain of $2.3 \mathrm{~kg}(2.2 \%)$ after one year.

\section{Lung function tests}

The table and figure 1 show the mean changes in lung function variables. The increase in PEF $(\%$ of predicted) at the end of the dieting period in the treatment group compared with the controls was not significant $\left(\mathrm{P}=0.06\right.$, table). The $\mathrm{FEV}_{1}(\%$ of predicted $)$ increased significantly more in the treatment group than in the controls. Even after one year, the difference was $7.6 \%(95 \%$ confidence interval $1.5 \%$ to $13.8 \%$; $\mathrm{P}=0.02)$. The FVC ( $\%$ of predicted) improved in the treatment group and decreased in the controls. After one year the difference was $7.6 \%(3.5 \%$ to $11.8 \%$; $\mathrm{P}=0.001)$. Analysis of variance for repeated measurements showed a significant difference between groups for the $\mathrm{FEV}_{1}(7.9 \%(3.4 \%$ to $12.4 \%) ; \mathrm{P}=0.001)$ and for the FVC $(7.9 \%(4.4 \%$ to $11.4 \%) ; \mathrm{P}=0.0001)$. For the PEF the difference was $5.1 \%(-1.2 \%$ to $11.4 \%$; $\mathrm{P}=0.11)$. The period effects and interaction effects were not significant.

\section{Symptoms}

Changes in cough, dyspnoea and use of rescue medication are shown in figure 2. By the end of the weight reduction programme the median reduction in dyspnoea in the treatment group was $13 \mathrm{~mm}$ on the visual analogue scale (1 $\mathrm{mm}$ in the controls). The daily use of rescue sympathomimetics decreased by 1.2 doses (median) in the treatment group ( 0.1 doses in the controls). For dyspnoea the $\mathrm{P}$ values for the difference in scores between groups were $\mathrm{P}=0.09$ at the end of the dieting period, $\mathrm{P}=0.02$ at the end of the weight reduction programme, $\mathrm{P}=0.09$ at 6 months, and $\mathrm{P}=0.12$ after one year. Corresponding $\mathrm{P}$ values for

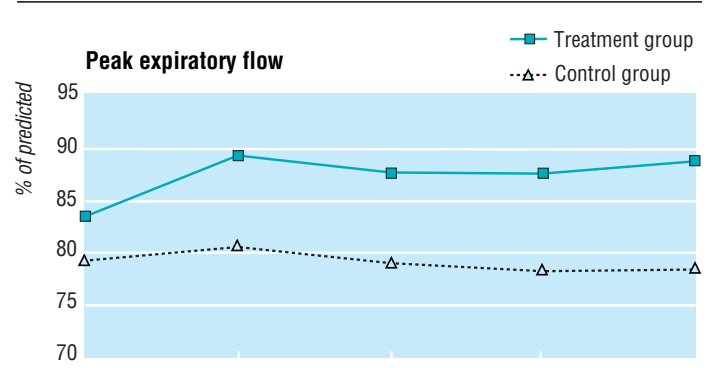

Forced expiratory volume in one second
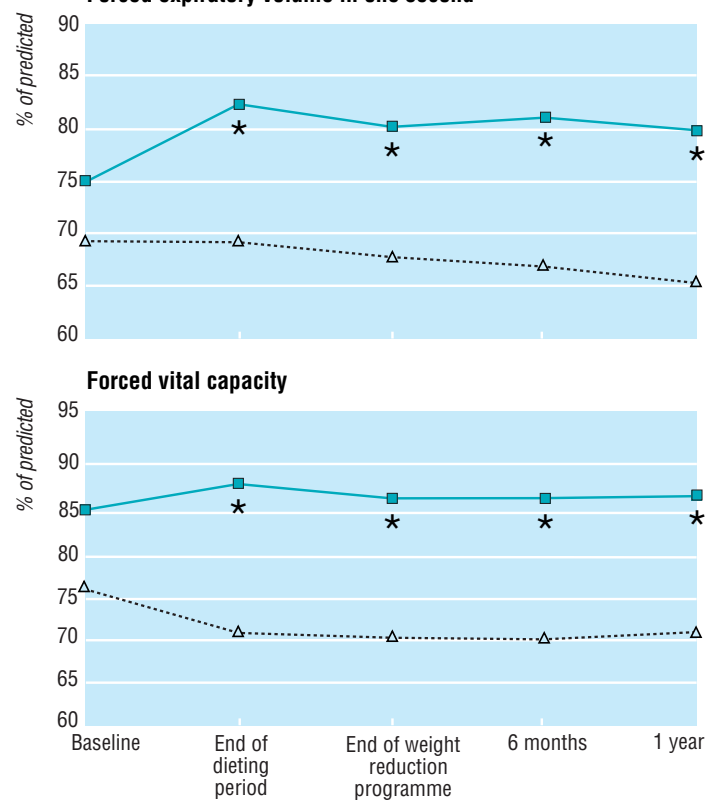

Fig 1 Mean morning premedication values for PEF, FEV (\% of predicted) at different stages during study. Vertical bars show standard errors of the mean. ${ }^{*}$ Change from baseline shows significant $(P<0.05)$ difference between groups (see table for $P$ values) 

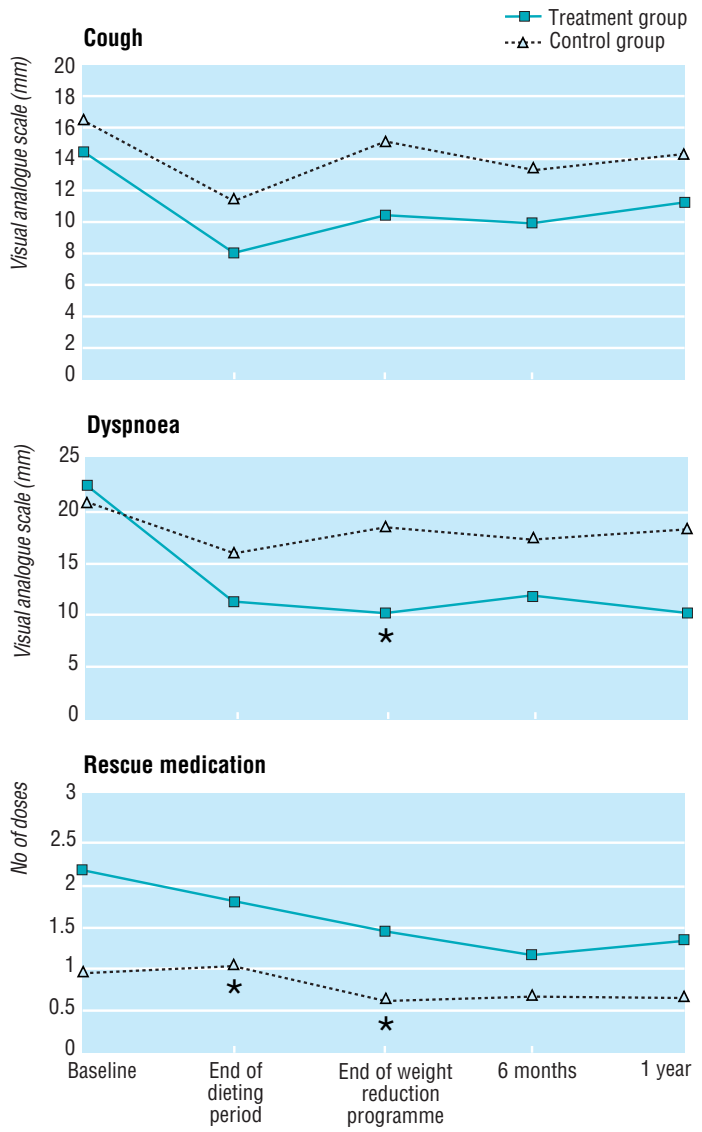

Fig 2 Mean values for cough and dyspnoea ( $\mathrm{mm}$ on visual analogue scale) and mean number of daily rescue medication doses at different stages during study. ${ }^{\star}$ Change from baseline shows significant $(P<0.05)$ difference between groups (see text for $P$ values)

rescue medication were $\mathrm{P}=0.02, \mathrm{P}=0.03, \mathrm{P}=0.10$, and $\mathrm{P}=0.08$. The changes in cough were non-significant (fig 2).

In the secondary analyses, the overall median change in dyspnoea was $-13 \mathrm{~mm}$ in the treatment group ( $-2 \mathrm{~mm}$ in the controls) $(\mathrm{P}=0.03)$. The overall change in cough was $-1.8 \mathrm{~mm}$ in the treatment group $(-1.3 \mathrm{~mm}$ in the controls) $(\mathrm{P}=0.67)$. Overall reduction in rescue medication was 0.5 doses and zero doses respectively $(\mathrm{P}=0.002)$. During the year of follow up, 18 participants in the control group and 16 in the treatment group experienced at least one exacerbation of their asthma. The median number of exacerbations was 1 (range $0-7$ ) in the control group and $1(0-4)$ in the treatment group $(\mathrm{P}=0.001)$. Thirteen controls and 10 participants in the treatment group needed a course of oral steroids $(\mathrm{P}=0.07)$. The median number of courses of oral steroids was two (0-3) in the control group and one (0-4) in the treatment group.

\section{Health status}

For the treatment group, health status improved with respect to all three subscales when compared with controls (fig 3). After one year the difference between groups was $-12(95 \%$ confidence interval -22 to -1 ; $\mathrm{P}=0.04)$ for symptom scores; $-9(-19$ to $1 ; \mathrm{P}=0.07)$ for activity scores; $-8(-17$ to $2 ; \mathrm{P}=0.10)$ for impact scores; and $-10(-18$ to $-1 ; \mathrm{P}=0.02)$ for total scores.

\section{Laboratory values}

During the weight reduction programme, no significant changes occurred in serum or urine cortisol concentration or in the urinary excretion concentrations of sodium, calcium, magnesium, or phosphorus. At the end of the dieting period, the mean urinary excretion concentration of sodium decreased significantly in the treatment group compared with the control group (112 (SD 54) $\mathrm{mmol} / \mathrm{l}$ to 44 (22) $\mathrm{mmol} / \mathrm{l}$ v 124 (42) $\mathrm{mmol} / \mathrm{l}$ to $115(34) \mathrm{mmol} / \mathrm{l} ; \mathrm{P}=0.01)$. The corresponding figures for magnesium were 2.8 (1.1) to 1.5 (1.1) and 3.1 (1.1) to $2.6(0.9)(\mathrm{P}=0.004)$. The serum concentrations for sodium, potassium, calcium, and magnesium fell within normal limits, never differing between groups throughout the study.
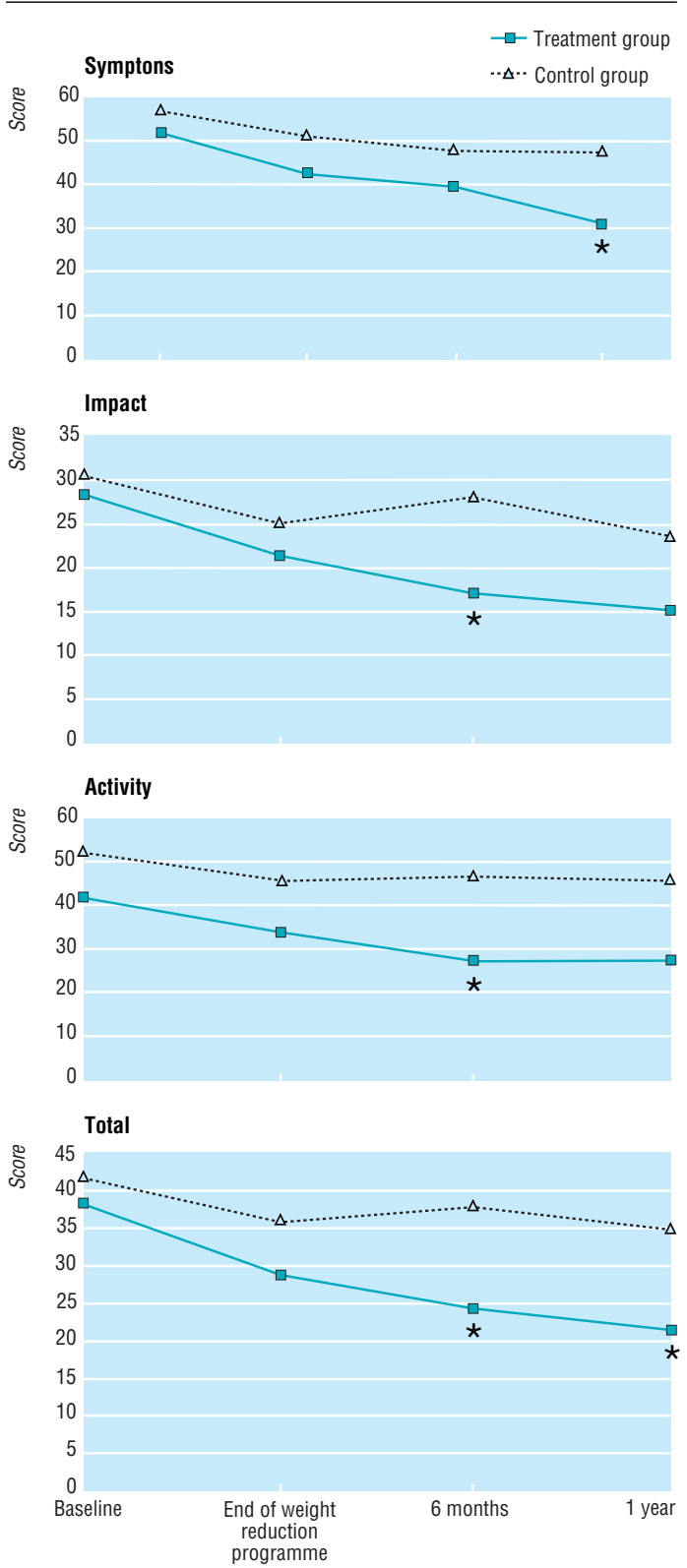

Fig 3 Health status: mean scores for symptoms, impact, and activity, and mean total scores, according to St George's respiratory questionnaire. ${ }^{*}$ Change from baseline shows significant $(P<0.05)$ difference between groups (see text for $\mathrm{P}$ values) 


\section{Discussion}

This trial showed that in obese people with asthma losing weight can improve asthma in terms of lung function, symptoms, and health status. Several possible explanations exist for this improvement in asthma during and after weight reduction. In asthma, airway obstruction causes early airway closure during expiration. This feature is accentuated by overweight, especially when patients are lying down. ${ }^{2}$ Weight reduction reduces closing capacity-that is, dependent airways close later in expiration-which tends to increase the forced expiratory volume in one second and the forced vital capacity. In asthmatic people, this may also lead to a reduction in clinical symptoms. Weight reduction also reduces the exercise load, which may alleviate asthma symptoms during exercise. Gastrointestinal reflux may worsen asthma symptoms, ${ }^{12}$ and reduction of fat around the abdomen may reduce reflux, thus alleviating symptoms. The psychological benefit of having lost weight may also alleviate symptoms.

Although general symptoms and lung function improved in the treatment group, use of rescue medication remained unchanged. This may reflect the fact that, whereas the overall clinical picture of the asthma was improved by the weight reduction, airway hyperreactivity persisted. No investigations into hyperreactivity during weight reduction have so far been reported. The decrease in urinary concentrations of sodium and magnesium during the weight reduction programme probably did not influence asthma symptoms. Low sodium intake may alleviate asthma, ${ }^{13}$ but other evidence shows that reduced magnesium intake may worsen it. ${ }^{14}$

The weight reduction regimen was well tolerated by the participants and caused no problems with medication and no exacerbations of the asthma. Nine months after the weight reduction programme began, all 19 participants in the treatment group had lost more than $5 \%$, and 17 more than $10 \%$, of their original weight. This shows satisfactory weight loss and maintenance. ${ }^{15}$ The fact that no participants dropped out and asthma symptoms improved suggests that a weight reduction programme based on a very low energy dietary preparation is acceptable for patients with asthma. Allergy to any of the ingredients in the preparation, however, should be taken into consideration.

This weight reduction programme was suitable for groups, and its 12 sessions were fewer than in most current programmes. ${ }^{16} \mathrm{~A}$ trained nurse for group supervision currently costs about $£ 1050$ (\$1680) in Finland; the cost per patient would therefore depend on the size of the group. In the clinical setting the additional costs are low because no routine laboratory tests are required, and patients usually purchase their own dietary preparations. We believe therefore that this weight reduction regimen is suitable for clinical work and that the benefits associated with weight reduction in obese patients with asthma can be achieved at reasonable cost.

The nature of the intervention was such that the trial could not be blinded. After randomisation the members of the control group might have felt disappointed, which could have influenced their evalu-
What is already known on this topic

Weight reduction has been shown to improve lung function in obese people

The influence of weight reduction on asthma in obese people has not been investigated

\section{What this study adds}

Weight reduction significantly improves forced expiratory volume in one second, forced vital capacity, and health status in obese people with asthma

With weight reduction the numbers of exacerbations and courses of oral steroids can also be reduced

Efforts should focus on making weight reduction part of the treatment of asthma in these patients

ation of symptoms and health status. Within the trial regimen, however, the control group received similar attention as often as the treatment group; in addition, controls were offered a similar weight reduction programme to start immediately after the trial.

We thank specialist nurses Anne Nurmikumpu, Päivi Helin, and Marjaana Korpinen for keeping the study together and the records in order, for help with arranging the programme for the control group, and for supervising the weight reducing regimen; Professor P W Jones for supplying the software application and instructions for analysing the health status data; Ms Terttu Kovanen for creating the database; Ms Heli Tofferi-Saarinen and Ms Sirpa Huhtaniitty for computer assistance and finalising the manuscript; Dr Carol Norris for language editing; and the participants for their patience in making this study possible.

Contributors: BS-A had the original idea for the study, designed the protocol, participated in the active investigation, and wrote the paper. PM supervised the weight reduction programme, revised the manuscript, and wrote the sections on weight loss. TP was responsible for the data analysis methodology and wrote the sections on statistical methods. JK compiled the health status data. E-LG and MY participated in the planning of the study, the practical work, and the creation of the database. BS-A is the guarantor for the paper.

Funding: The Finnish Culture Foundation, the Association of the Pulmonary Disabled, and the Wilhelm and Else Stockmann Foundation. Nycomed Pharma supplied the dietary preparation (Nutrilett) free of charge.

Competing interests: None declared.

1 Seidell JC, Flegal KM. Assessing obesity: classification and epidemiology. Br Med Bull 1997;53:238-52.

2 Hakala K, Mustajoki P, Aittomäki J, Sovijärvi ARA. Effect of weight loss and body position on pulmonary function and gas-exchange abnormalities in morbid obesity. Int J Obesity 1995;19:343-6.

3 Gall H, Gorck G, Kalveram K-J, von Lersner-Lenders S. Soforttypallergie auf Hülsenfrüchte (Leguminosen) [Immediate type allergy to legume food]. Allergologie 1990;13:352-5.

4 Pekkarinen T, Takala I, Mustajoki P. Two-year maintenance of weight loss after a VLCD and behavioural therapy for obesity: correlation with the scores of questionnaires measuring eating behaviour. Int J Obesity 1996;20:332-7

5 Pekkarinen T, Mustajoki P. Comparison of behavioural therapy with and without very low-energy diet in the treatment of morbid obesity. Arch Intern Med 1997;157:1581-5.

6 Mustajoki P. Treatment of individuals who are obese. Behaviour modification and other aspects. Disease Management and Health Outcomes 1998:4:267-75.

7 Jones PW, Nedochromil Sodium Quality of Life Study Group. Quality of life, symptoms and pulmonary function in asthma: long-term treatment with nedochromil sodium examined in a controlled multicentre trial. Eu Respir J 1994;7:55-62.

8 Santanello NC, Zhang J, Seidenberg B, Reiss TF, Barber BL. What are minimal changes for asthma measures in a clinical trial? Eur Respir J 1999;14:23-7. 
9 Pocock SJ. Clinical trials. A practical approach. 5th ed. New York: Wiley, 1988:124-5.

10 Nunn JA, Gregg I. New regression equations for predicting peak expiratory flow in adults. $B M J$ 1989;289:1068-70.

11 Viljanen A, ed. Reference values for spirometric, pulmonary diffusing capacity and body pletysmographic studies. Scand Clin Invest 1982;42(suppl 159):1-50.

12 Harding SM, Richter JE. The role of gastroesophageal reflux in chronic cough and asthma. Chest 1997;111:1389-402

13 Carey OJ, Locke C, Cookson JB. Effect of alterations of dietary sodium on the severity of asthma in men. Thorax 1993;48:714-8.
14 Hill J, Micklewright A, Lewis S, Britton J. Investigation of the effect of short-term change in dietary magnesium intake in asthma. Eur Respir J 1997;10:2225-9.

15 Glenny A-M, O'Meara S, Melville A, Sheldon TA, Wilson C. The treatment and prevention of obesity: a systematic review of the literature. Int J Obesity 1997;21:715-37.

16 Wing RR. Behavioural approaches to the treatment of obesity. In: Bray GA, Bouchard C, James WPT, eds. Handbook of obesity. New York: Marcel Dekker, 1998:855-73.

(Accepted 11 January 2000)

\title{
Trainee satisfaction before and after the Calman reforms of specialist training: questionnaire survey
}

\author{
Elisabeth Paice, Maryanne Aitken, George Cowan, Shelley Heard
}

\begin{abstract}
Editorial by Catto
North Thames

Department of

Postgraduate

Medical and Dental

Education, London

WC1N 3EJ

Elisabeth Paice

dean director

Maryanne Aitken

project manager

George Cowan

postgraduate dean

Shelley Heard

postgraduate dean

Correspondence to:

E Paice

epaice@tpmde.ac.uk
\end{abstract}

BMJ 2000;320:832-6

\begin{abstract}
Objectives To evaluate the impact of the Calman reforms of higher specialist training on trainee satisfaction.

Design Questionnaire surveys using portable electronic survey units, two years apart.

Setting Postgraduate, teaching, district general, and community NHS trusts in North Thames. North Thames deanery includes London north of the Thames, Essex, and Hertfordshire.

Participants Trainees in all grades and all specialties: 3078 took part in the first survey and 3517 in the second survey.

Main outcome measures Trainees' satisfaction with training in their current post, including educational objectives, training agreements, induction, consultant feedback, hands on experience acquired, use of log books, consultant supervision, and overall satisfaction with the post.

Results In the second survey respondents were more likely to have discussed educational objectives with their consultant, used a log book, and had useful feedback from their consultant. They were more likely to give high ratings to induction, consultant supervision, and hands on experience acquired in the post. Each of these elements was associated with increased satisfaction with the post overall.

Improvements were most noticeable at the level of specialist registrar, but changes in the same direction were also seen in more junior grades.

Conclusions After the reforms of specialist training, trainees in all grades reported greater satisfaction with their current posts. The changes required extra training time and effort from consultants.
\end{abstract}

\section{Introduction}

In 1992 Kenneth Calman, then chief medical officer, set up a working group to bring the British system of specialist training into line with the requirements of the European medical directives. The resulting report recommended combining the registrar and senior registrar grades into a unified specialist registrar grade and defining the curriculum and minimum training period for each specialty, the successful completion of which would lead to admission to the specialist register. ${ }^{1}$ Features of the new system were set out in A Guide to
Specialist Registrar Training and included educational objective setting, training agreements, and induction at the start of each placement; rotational placements designed to offer specified experience; and regular feedback on progress from the supervising consultant. ${ }^{2}$ The reforms were to be cost neutral, and no additional resources were made available to NHS trusts for their implementation. Transition to the new system began in December 1995 and was completed in April 1997.

The new arrangements placed more emphasis on structured teaching and supervised learning and less on experiential apprenticeship. ${ }^{3}$ Although the reforms received a cautious welcome, ${ }^{4-6}$ there were anxieties about the impact of shortening the training time on trainees' experience ${ }^{7}$ especially since junior doctors' hours were being reduced. ${ }^{8}$ It was expected that the reforms would lead to fewer trainees and more consultants. $^{9}$ Consultants feared they would be expected to take on extra responsibility for out of hours emergency work, including resident on-call, ${ }^{10} 11$ although this was denied by senior doctors involved in planning the reforms. ${ }^{12}{ }^{13}$ The implementation of the reforms seemed likely to create a major new training workload for consultants. ${ }^{14}$ At the same time they were losing control over appointment of their own junior colleagues, who were to be appointed to regional programmes and allocated to posts by a regional committee. It was not clear whether the reforms could be delivered without additional resources, how motivated the consultants would be to implement change, whether higher specialist trainees would consider their training improved, or what the impact would be on the training of more junior grades.

To evaluate the impact of the reforms on specialist registrars (including old style registrars and senior registrars) and any knock-on effects on more junior grades (preregistration house officers and senior house officers), we planned two surveys of trainees in all grades and all specialties in our region: one during transition to the new system and one two years later.

\section{Participants and methods}

\section{Surveys}

The first survey took place during transition in November and December 1996, with postal questionnaires to non-responders in January 1997. The second survey took place 18 months after transition was 